\title{
Correlations between opioid mortality increases related to illicit/synthetic opioids and reductions of medical opioid dispensing - exploratory analyses from Canada
}

Benedikt Fischer ${ }^{1,2,3,4^{*}}$ (D), Wayne Jones ${ }^{3}$, Mark Tyndall ${ }^{5}$ and Paul Kurdyak $k^{6,7}$

\begin{abstract}
Background: North America has been experiencing a persistent epidemic of opioid-related overdose mortality, which has increasingly been driven by fatalities from illicit, toxic opioids in most recent years. Patterns of synthetic opioid availability and related mortality are heterogeneous across Canada, and differing explanations exist as to their differentiated proliferation. We examined the perspective that heterogeneous province-based variations in prescription opioid availability, facilitated by various control strategies, post-2010 may have created regionally differential supply gaps for non-medical opioid use substituted by synthetic opioid products with differential impacts on mortality risks and outcomes in Canada.
\end{abstract}

Methods: We examined annual, prescription opioid dispensing rates and changes in the ten Canadian provinces (for the periods of 1) 2011-2018, 2) 'peak-year'-to-2018) in Defined Daily Doses/1000 population/day, derived from data from a large representative, stratified sample of community pharmacies projected to a Canada total. Annual, provincial opioid-related mortality rates and changes for years 2016-2018 were calculated from federal data. We computed correlation values (Pearson's R) between respective province-based change rates for prescription opioid dispensing and opioid-related mortality for the two over-time scenarios.

Results: All but one province featured reductions in prescription opioid dispensing 2011-2018; seven of the ten provinces had increases in opioid mortality 2016-2018. The correlation between changes in opioid dispensing (20112018) and in opioid-mortality (2016-2018) was $r=0.63$ ( $\mathrm{df}=8, p$-value: 0.05); the correlation was $r=0.57(\mathrm{df}=8$, $p$-value: 0.09) for changes in opioid dispensing 'peak year'-to-2018, respectively.

Conclusions: Quasi-significant results indicate that recent increases in opioid-related deaths driven by illicit, synthetic opioids tended to be larger in provinces where reductions in prescription opioid availability have been more extensive. It is a plausible explanation that these reductions created supply gaps for non-medical opioid use increasingly filled by illicit, synthetic opioids differentially contributing to opioid-related deaths, generating un-intended adverse effects for previous interventions. General prevention measures to reduce opioid availability, and targeted prevention for at-risk opioid users exposed to toxic drug supply may be include counteractive effects and require coordinated reconciliation.

Keywords: Prescription opioids, Mortality, Synthetic opioids, Non-medical use, Supply, Substitution, Public health, Canada

\footnotetext{
* Correspondence: bfischer@sfu.ca

${ }^{1}$ Schools of Population Health and Pharmacy, Faculty of Medical and Health

Sciences, University of Auckland, 85 Park Rd, Grafton, Auckland 1023, New

Zealand

${ }^{2}$ Department of Psychiatry, University of Toronto, Toronto, ON, Canada

Full list of author information is available at the end of the article
}

(c) The Author(s). 2020 Open Access This article is distributed under the terms of the Creative Commons Attribution 4.0 International License (http://creativecommons.org/licenses/by/4.0/), which permits unrestricted use, distribution, and reproduction in any medium, provided you give appropriate credit to the original author(s) and the source, provide a link to the Creative Commons license, and indicate if changes were made. The Creative Commons Public Domain Dedication waiver (http://creativecommons.org/publicdomain/zero/1.0/) applies to the data made available in this article, unless otherwise stated. 


\section{Background}

North America continues to experience an unprecedented public health crisis involving an extensive toll of opioidrelated poisonings and mortality. Concretely, there were 47,600 opioid-related deaths in the US in 2017, and 4460 opioid-related deaths in Canada in 2018. While patterns regionally differ in both countries, these mortality numbers represent $\sim 10 \%$ increases over previous years as well as yet similar country-based population rates [1,2].

Opioid-related mortality in North America - and Canada specifically - was originally driven by high, and rising levels of medical opioid dispensing; however, these ecological parameters have shifted in recent years. Specifically, following a variety of system-level interventions to restrain opioid use and harms (e.g., select opioid formulation control; restrictive prescription guidelines and monitoring; enforcement) and increasing public awareness post-2010, a deceleration in medical opioid dispensing - albeit with substantial regional variations - occurred across North America [3, 4]. Based on standardized population-level measures (e.g., morphine equivalents or defined daily doses/capita), medical opioid dispensing declined by about $20 \%$ during the period 2010/2011 to 2015/2016 in both the US and Canada $[5,6]$. In Canada, these declines had further accelerated by 2018 , with reductions of up to $50 \%$ in medical PO dispensing - a halving of the population-level flow of prescribed opioids within just a few years - in some Canadian provinces (e.g., British Columbia, where strict opioid prescribing standards based on US prescribing guidelines were introduced in 2016) [7, 8]. In addition, heroin vanished from most local drug markets amidst rising prescription opioid availability without substantial return.

The discrepant developments of decreasing opioid availability and increasing opioid mortality have been explained mainly with the recent proliferation and use of new illicitly produced, highly potent and toxic synthetic opioid products (e.g., fentanyl or fentanyl analogues) [9, 10] which have greatly amplified the risk for overdose and fatalities among non-medical users. Recently, synthetic opioids have been implicated in substantial but regionally inconsistent proportions of opioid-related deaths (province-based range: $5-88 \%$ in 2018) [1]. As local availability and contribution of illicit/synthetic opioids to mortality has varied across North America, key questions regarding the drivers of these inconsistent patterns exist. While some explain the arrival of illicit/synthetic opioids as an independent supply 'wave', other perspectives have suggested that they have proliferated primarily as a direct consequence of substantially reduced availability of medically-dispensed opioids for non-medical use ('supply gap' theory) [11-13]. This perspective has been corroborated by various data on nonmedical opioid use trajectories initiated with prescription opioids and transitioning to riskier opioid use modes (e.g., injecting) and/or illicit/synthetic opioid products among sub-populations of users [14, 15].

In the context of the above dynamics, the 'supply gap' perspective may suggest that jurisdictions with larger reductions in prescription opioid dispensing (involving lesser availability of medical opioids and greater illicit opioid exposure) would experience larger increases in opioid-associated risk and mortality among non-medical users. To examine the above perspective, we explored associations between recent, provincial patterns of over-time changes in medical opioid dispensing and corresponding changes in opioid-related mortality across Canada in the post-2010 period.

\section{Methods}

Data used for analyses were obtained from two sources. First, medical opioid dispensing data came from previously examined information on community-based (retail) dispensing of prescribed opioid medications collected through a commercially assembled, stratified, representative ('IQVIA', formerly IMS Compuscript) pan-Canadian panel of about 6000 community-based pharmacies from which the total of national opioid dispensing in Canada is estimated by-way-of geospatial projection methodology, as used by similar drug utilization analyses [5, 16-18]. Original dispensing information included opioid product name, formulation, strength and dose, by province for the study period. Based on the WHO's 'Pain Ladder' and Anatomical Therapeutic Chemical (ATC) classification, 'strong opioids' (i.e., excluding 'weak' opioids, as well as methadone due to inconsistent dispensing) were categorized and converted into annual Defined Daily Doses/1000 population/ day (DDD/1000/day, a standard comparative drug utilization measure) values for the ten provinces for years 2011-2018 [19, 20]. Based on these annual, province-based opioid dispensing rates, we derived, a priori, two measures for subsequent analyses. The first measure was the differences in annual, province-based opioid dispensing (in DDD/1000/day) between 2011 and 2018; the second was the difference between each province's 'peak-year' of opioid dispensing rate over the period 2011 to 2017 and the corresponding province's 2018 rate. The rationale for these two measures was that 1) in Canada, key control interventions (e.g., select strong opioid delisting from public formularies, intensified prescription monitoring and /or guidelines for prescription opioids) targeting prescription opioid availability and use began in 2012 (i.e., with 2011 as last preintervention year), 2) opioid dispensing changes have varied substantially, e.g. in terms of timing, by province across Canada [5, 21] [see linegraph, Fig. 1].

Second, for opioid-related mortality we used available, annual population rates (per 100,000) of apparent opioid-related deaths, for the ten provinces, as reported by federal authorities for the three years 2016, 2017 and 2018 (only full years available for these data) [1]. The 

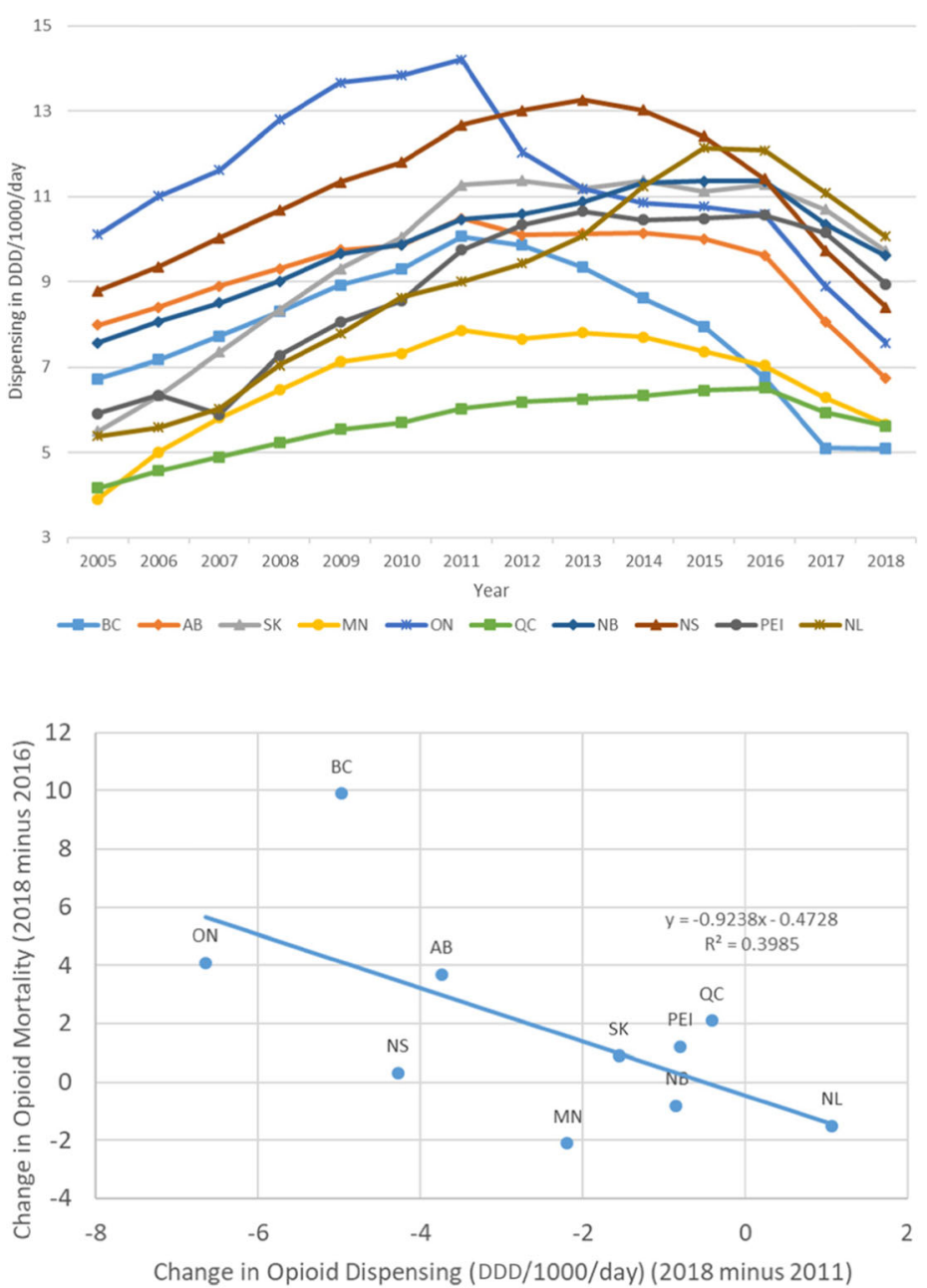

- Change in Dispensing from 2011 to 2018 and Change in Mortality from 2016 to 2018

_ Linear (Change in Dispensing from 2011 to 2018 and Change in Mortality from 2016 to 2018)

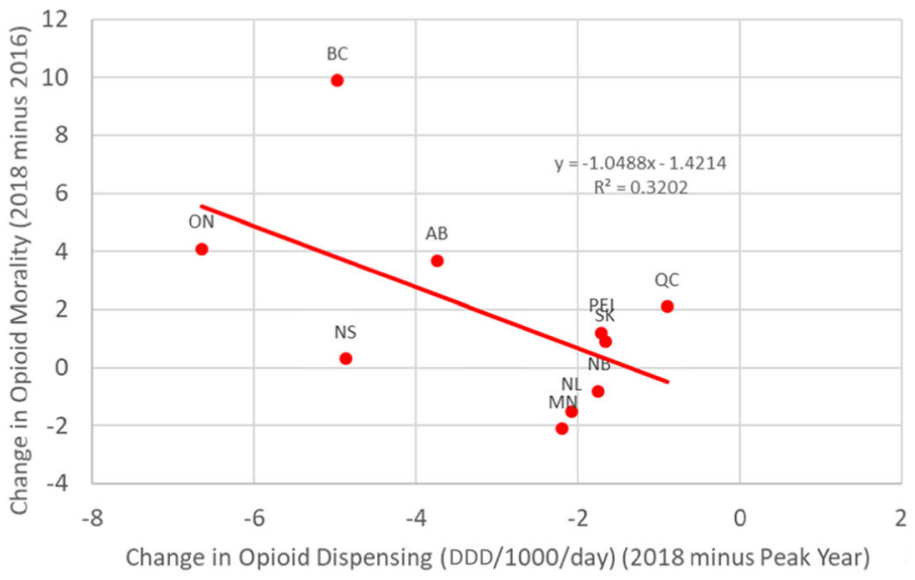

- Change in Dispensing from Peak Year to 2018 and Change in Mortality from 2016 to 2018

_Linear (Change in Dispensing from Peak Year to 2018 and Change in Mortality from 2016 to 2018)

Fig. 1 (1) Line-graph of province-based opioid dispensing (in DDD/1000/day) for years 2005-2018 and (2) scatterplots of correlations of changes in annual opioid dispensing (2a) 2018-2011 and (2b) 2018 - 'peak year' and opioid-related mortality (2018-2016) in Canada 
national opioid-related mortality data are based on investigations by provincial coroner services examining suspected unnatural deaths for drug-related causes. For this measure, the 2016 opioid-related mortality rate was subtracted from the 2018 rate for each province.

Based on the investigation's focus on possible associations between the two above-defined outcomes, the statistic of interest was the Pearson product moment correlation values between the two sets of province-based changes in opioid dispensing rates [1] 2018-2011, and [2] 2018 -- provincial 'peak year' and the corresponding changes in annual, province-based opioid-related mortality rate (2018 to 2016). Correlation statistics were reported, and scatterplots for visualizations of the two correlations were generated. All analyses were computed in Microsoft Excel 2016.

No ethics review was required for this study due to the fully anonymous, de-personalized nature of the data used and analyses conducted.

\section{Results}

[see Table 1, also for definition of acronyms of provinces, as well as linegraph, Fig. 1] For provincial, annual opioid dispensing, all but one province featured a decrease in rates over the period 2011-2018; all ten provinces featured a decrease when considering 'peak year-to-2018'. ON had the highest opioid dispensing rate (14.2 DDD/1000/day), QC the lowest (6.0 DDD/1000/day) rate in 2011; in 2018, NL had the highest (10.1 DDD/1000/day) and BC had the lowest opioid dispensing rate (5.1 DDD/1000/day). Between 2011 and 2018, ON had the largest reduction (6.7 DDD/ 1000/day), whereas NL had a small increase (1.1 DDD/ 1000/day) in opioid dispensing; for 'peak-to-2018', ON had the largest reduction $(6.7 \mathrm{DDD} / 1000 /$ day $)$ and QC had the smallest reduction (0.9 DDD/1000/day).

For opioid-related mortality, seven provinces had increases and three featured decreases in opioid-related mortality rates between 2016 and 2018. BC had the respective highest rates (20.7 deaths/100,000 population, $30.8 / 100,000$, and $30.6 / 100,000)$ in all three years $(2016-$ $2018)$; the respectively lowest annual rates were QC $(3.0 / 100,000)$, PEI $(2.7 / 100,000)$ and NL $(1.9 / 100,000)$. The largest increase in the opioid mortality rate was in BC $(9.9 / 100,000)$, whereas the largest decrease was in MN (2.1/100,000) 2016-2018.

[See scatterplots in Fig. 1] The correlation between 1) changes in opioid dispensing (2011-2018) and changes in opioid-mortality $(2016-2018)$ was $0.63(\mathrm{df}=8, p$-value $=$ $0.05)$; for 2) the changes 'peak year'-to-2018' and corresponding changes in opioid-mortality (2016-2018) the correlation was $0.57(\mathrm{df}=8, p$-value $=0.09)$. Both sets of correlations were in the predicted direction; results were quasi-significant or borderline-significant, respectively.

\section{Discussion}

In the above, we have shown quasi-significant correlations between recent (post-2010) changes in medical opioid dispensing and opioid-related mortality rates across Canada's ten provinces. These findings come in a wider context of mostly substantial, yet provincially heterogeneous reductions in prescription opioid dispensing and equally extensive, yet equally heterogeneous changes - mostly by way of increases - in opioid-related mortality in Canada $[1,5]$. The unprecedented increases in opioid overdose fatalities - outnumbering other major unnatural death categories and negatively impacting population-level life expectancy - have not been effectively addressed by interventions to date and require improved causal analyses towards improved intervention strategies [12, 22].

The recent major increases in opioid-related deaths have mainly been attributed to the sudden, pan-North American proliferation of potent and toxic illicit/synthetic opioid products (e.g., fentanyl and analogues). These illicit, mostly foreign produced opioid products, began to initially appear and boost opioid-related mortality in Canada (similar to the US, where increasing heroin use contributed to higher fatality rates) around 2015 [9, 23, 24]. These descriptive details, however, neither sufficiently explain the differential proliferation patterns, nor the highly differential contribution rates of these illicit opioid products to opioid-related mortality (range by province: $11-$ $68 \%$ [2016]; 5-88\% [2018]) across Canada [1].

Varying explanation approaches for the above developments exist. One is that illicit opioid supplies suddenly emerged on non-medical opioid markets as an independent supply 'wave' resulting in the described spikes of opioid mortality; this model however falls short of explaining the stark regional heterogeneity in illicit/synthetic opioid availability and their contributions to fatalities [13, 23]. A possibly different explanation - furthered elsewhere - is that illicit/synthetic opioid products proliferated as a wider substitution dynamic in response to reductions of and emerging gaps in medical opioid availability following various restrictive opioid control strategies implemented, with large populations of individuals previously exposed to (medical and nonmedical) opioid use during previous periods of ample availability $[23,25]$. At peak times (around 2010), $>20 \%$ of Canadians reported past-year use of prescription opioids, and > $5 \%$ were involved in non-medical use of opioids, translating into high levels of exposure in the general population [26]. Once the various opioid control measures became ramped up, large numbers of non-medical opioid users (including but not limited to use disorders) presumably needed to increasingly rely on both riskier (e.g., injecting) use practices as well as utilize new opioid supply sources - including illicit/synthetic opioid products - to meet their opioid demand needs, resulting in swiftly accelerating overdose and consequential fatality incidents $[9,15,27]$. 
Table 1 Annual opioid dispensing (1) 2018-2011 and (2) 2018 - 'peak year' and change rates, and opioid-related mortality (20182016) and change rates, by province in Canada.

\begin{tabular}{|c|r|r|r|r|r|r|r|r|}
\hline & \multicolumn{3}{|c|}{$\begin{array}{c}\text { Opioid Dispensing } \\
\text { (ddd/1000/day) }\end{array}$} & $\begin{array}{c}\text { Change in Opioid } \\
\text { Dispensing }\end{array}$ & $\begin{array}{c}\text { Opioid Mortality } \\
\text { (/100,000) }\end{array}$ & $\begin{array}{c}\text { Change in } \\
\text { Opioid } \\
\text { Mortality }\end{array}$ \\
Province & 2011 & Peak Year & 2018 & $\begin{array}{c}2018- \\
2011\end{array}$ & $\begin{array}{c}2018-\text { Peak } \\
\text { Year }\end{array}$ & 2016 & 2018 & $2018-2016$ \\
\hline BC & 10.1 & $10.1(2011)$ & 5.1 & -5.0 & -5.0 & 20.7 & 30.6 & 9.9 \\
AB & 10.5 & $10.5(2011)$ & 6.7 & -3.7 & -3.7 & 14.3 & 18.0 & 3.7 \\
SK & 11.3 & $11.4(2012)$ & 9.7 & -1.6 & -1.7 & 7.3 & 8.2 & 0.9 \\
MN & 7.9 & $7.9(2013)$ & 5.7 & -2.2 & -2.2 & 6.7 & 4.6 & -2.1 \\
ON & 14.2 & $14.2(2011)$ & 7.6 & -6.7 & -6.7 & 6.2 & 10.3 & 4.1 \\
\hline QC & 6.0 & $6.5(2015)$ & 5.6 & -0.4 & -0.9 & 3.0 & 5.1 & 2.1 \\
NB & 10.5 & $11.4(2015)$ & 9.6 & -0.8 & -1.7 & 4.3 & 3.5 & -0.8 \\
NS & 12.7 & $13.3(2013)$ & 8.4 & -4.3 & -4.9 & 5.6 & 5.9 & 0.3 \\
PEI & 9.7 & $10.6(2016)$ & 8.9 & -0.8 & -1.7 & 3.4 & 4.6 & 1.2 \\
NL & 9.0 & $12.1(2015)$ & 10.1 & 1.1 & -2.1 & 3.4 & 1.9 & -1.5 \\
\hline
\end{tabular}

List of acronyms and full names of provinces: $B C=$ British Columbia; $A B=$ Alberta; $S K=$ Saskatchewan; $M N=M a n i t o b a ; O N$ = Ontario; $\mathrm{QC}=$ Quebec; NB = New Brunswick; NS = Nova Scotia; PEI = Prince Edward Island; NL = Newfoundland

List of acronyms and full names of provinces: BC British Columbia; $A B$ Alberta; SK Saskatchewan; MN Manitoba; ON Ontario; QC Quebec; NB New Brunswick; NS Nova Scotia; PEI Prince Edward Island; NL Newfoundland

Our results appear to at least initially corroborate and lend support to the latter explanation approach. Concretely, they support associations between the levels of province-based changes (mostly increases) in opioidrelated mortality and changes (mostly reductions) in medical opioid availability post-2010. Or, differently put: opioid mortality tended to rise more strongly in jurisdictions that reduced medical opioid availability more substantially during the study period. While the results had only limited statistical significance, the associations' consistent directionality and relative strength is notable given the small number of data points, specifically with only three years of opioid-mortality data available. Further noteworthy is that the observed decreases in opioidmortality occurred exclusively in (three) provinces with later (i.e., post-2011) reductions in opioid availability, suggesting possible lag effects. Overall, our examinations should be extended towards more comprehensive and rigorous analyses, ideally with expanded data for the benefit of increased power and analytical strength.

Despite data and methods limitations, the results suggest several key implications: First, as shown elsewhere, supply dynamics for psychoactive drug use - especially where alternative (e.g., medical and non-medical sources) exist appear to be both complex and dynamic; consequently, well-intended supply control measures can have unintended, adverse consequences, including substitutions towards more hazardous substances [28]. Thus, in the context of the Canadian opioid crisis, recent, while differential reductions in medical opioid availability to reduce opioidrelated health harms implemented post-2010 may have resulted in supply gaps subsequently filled by hazardous, illicit opioid products and consequential mortality increases. This furthermore implies that the existing, extensive 'demand side' for non-medical opioid use - despite substantially expanded prevention and treatment measures - has not been addressed commensurately with opioid supply reductions $[25,29,30]$. Overall, the totality of measures undertaken to reduce opioid-related health harms in Canada - where such efforts occur in a complex, multi-level system environment involving both, and at times conflicting, federal and provincial jurisdictions - since-2010 may have resulted in as much harm as benefit, including sudden, substantial spikes of mortality from illicit/synthetic opioids; hence, it is imperative to better understand the direct and indirect impacts of intervention measures towards at least improved policy development and design in the future [22, 28, 31].

Within these diverging developments facilitating Canada's opioid crisis, the concrete need to prevent opioid mortality among existent at-risk opioid users is acute and urgent. In current contexts, this principally requires effective measures to supply high-risk opioid users with safer (e.g., medical grade) opioid products to reduce illicit, toxic drug exposure and consequential fatality 
outcomes [12, 32, 33]. Small, locally limited 'safer opioid' distribution programs (e.g., in Vancouver: [34]) have been initiated; however, these provisions ought to be scaled-up widely towards reaching substantial proportions of at-risk users and reducing fatal overdose incidents. Notably, such public health emergency-based 'safer opioid' provisions are at direct odds with the system-level reductions in medical opioid dispensing undertaken; reconciling these efforts towards overall public health benefit requires improved systemcoordination of general prevention (i.e., reasonably limited opioid availability) to reduce undue opioid exposure in the general population with targeted prevention measures of safer opioid provision to reduce illicit/toxic opioid exposure among sub-populations of at-risk opioid users.

\section{Conclusions}

We provide evidence for possible, ecological associations between the extent of reductions in longstanding, high levels of medical opioid availability and levels of opioid mortality on provincial population-levels in Canada. Such a correlation would most likely be explained with illicit, toxic opioid products filling emerging gaps in overall opioid supply in light of persistently high demands for (medical or non-medical opioid use). While more detailed and rigorous analyses are needed to further confirm these possible mechanisms, our data underscore that a fine and complex balance towards overall improved public health urgently needs to be found between reasonable reductions in opioid dispensing for general prevention vis-à-vis effective, targeted prevention measures for existing at-risk opioid user populations in the present contexts of an unrelenting national opioid mortality crisis in Canada.

\section{Abbreviations \\ WHO: World Health Organization; ATC: Anatomical Therapeutic Chemical; DDD: Defined Daily Doses}

\section{Canadian Provinces}

AB: Alberta; BC: British Columbia; MB: Manitoba; NB: New Brunswick; NL: Newfoundland and Labrador; NS: Nova Scotia; ON: Ontario; PEl: Prince Edward Island; QC: Quebec; SK: Saskatchewan

\section{Acknowledgments}

The authors acknowledge Mrs. Lenka Vojtila for her skilled technical assistance in assembling the present manuscript.

\section{Authors' contributions}

BF conceptualized the study and prepared the initial and subsequent revision drafts of the paper. WJ lead the development of the analyses plan and conducted the statistical analyses. All authors (BF, WJ, MT, and PK) contributed to methodological adjustments, review of results and data interpretation, and provided substantial intellectual contributions to the content of iterative drafts of the paper. All authors approved the final manuscript submitted.

\section{Funding}

Dr. Fischer acknowledges research support from the Canadian Institutes of Health Research (CIHR), specifically grant \# SAF-94814, as well as from the Hugh Green Foundation Chair in Addiction Research, Faculty of Medical and Health Sciences, University of Auckland, New Zealand. Neither funder entities nor providers of data mentioned had any involvement in or influence over the study design, analyses, reporting or interpretation of the data.

\section{Availability of data and materials}

The datasets analysed for the present study included data extracted from a commercial database (IQVIA Canada's Compuscript) on medical

pharmaceutical (including opioid) prescriptions in Canada, and national data on opioid-related mortality (Health Canada). IQVIA's Compuscript data reporting on opioid prescriptions are commercially available on specific request from IQVIA Canada. National opioid-related mortality data used in this study is publically available from Health Canada through its public surveillance and information database (https://health-infobase.canada.ca/substance-relatedharms). Details related to the analyses of the data can be provided by the authors on reasonable request.

\section{Ethics approval and consent to participate}

Ethics approval was not required for this study due to the fully anonymous, de-personalized nature of the data used and analyses conducted (see also corresponding statement in Methods).

\section{Consent for publication}

Not Applicable.

\section{Competing interests}

The authors declare that they have no competing interests except for the research funding declared.

\section{Author details}

${ }^{1}$ Schools of Population Health and Pharmacy, Faculty of Medical and Health Sciences, University of Auckland, 85 Park Rd, Grafton, Auckland 1023, New Zealand. ${ }^{2}$ Department of Psychiatry, University of Toronto, Toronto, ON, Canada. ${ }^{3}$ Centre for Applied Research in Mental Health and Addiction (CARMHA), Faculty of Health Sciences, Simon Fraser University, Vancouver, BC, Canada. ${ }^{4}$ Department of Psychiatry, Federal University of São Paulo (UNIFESP), São Paulo, Brazil. ${ }^{5}$ School of Population and Public Health, University of British Columbia, Vancouver, Canada. ${ }^{6}$ Institute for Mental Health Policy Research, Centre for Addiction and Mental Health, Toronto, ON, Canada. ${ }^{7}$ Institute for Clinical Evaluative Sciences (ICES), Toronto, ON, Canada.

Received: 16 September 2019 Accepted: 13 January 2020

Published online: 31 January 2020

References

1. Public Health Agency of Canada. National Report: Apparent Opioid-related Deaths in Canada. Ottawa: Government of Canada; 2019. https://infobase. phac-aspc.gc.ca/datalab/national-surveillance-opioid-mortality.html. Accessed: August 15, 2019

2. Seth P, Scholl L, Rudd RA, Bacon S. Overdose deaths involving opioids, cocaine, and psychostimulants_-United States, 2015-2016. Morb Mortal Wkly Rep. 2018;67(12):349.

3. Fischer B, Rehm J, Tyndall M. Effective Canadian policy to reduce harms from prescription opioids: learning from past failures. CMAJ. 2016;188(1718):1240-4.

4. Kolodny A, Courtwright DT, Hwang CS, Kreiner P, Eadie $L$, Clark TW, et al. The prescription opioid and heroin crisis: a public health approach to an epidemic of addiction. Annu Rev Public Health. 2015;36:559-74.

5. Fischer B, Jones W, Vojtila L, Kurdyak P. Patterns, changes, and trends in prescription opioid dispensing in Canada, 2005-2016. Pain Physician. 2018; 21(3):219-28.

6. Guy GP Jr, Zhand K, Bohm MK, Losby J, Lewis B, Young R, et al. Vital signs: changes in opioid prescribing in the United States, 2006-2015. MMWR. 2017:66(26):697.

7. Fischer B, Jones W, Vojtila L, Kurdyak P. Prescription opioid dispensing in Canada: An update on recent developments until 2018. Vancouver: Centre for Applied Research in Mental Health and Addiction; 2019. 
8. Dowell D, Haegerich TM, Chou R. CDC guideline for prescribing opioids for chronic pain—United States, 2016. JAMA. 2016;315(15):1624-45.

9. Ciccarone D. Fentanyl in the US heroin supply: a rapidly changing risk environment. Int J Drug Policy. 2017:46:107-11.

10. Suzuki J, El-Haddad S. A review: fentanyl and non-pharmaceutical fentanyls. Drug Alcohol Depend. 2017;171:107-16.

11. Martin J, Cunliffe J, Décary-Hétu D, Aldridge J. Effect of restricting the legal supply of prescription opioids on buying through online illicit marketplaces: interrupted time series analysis. Br Med J. 2018;361:k2270.

12. Fischer B, Pang M, Tyndall M. The opioid death crisis in Canada: crucial lessons for public health. Lancet Public Health. 2018;4(2):e81-e2.

13. Ciccarone D. The triple wave epidemic: supply and demand drivers of the US opioid overdose crisis. Int J Drug Policy. 2019;71:183-8.

14. Mars SG, Rosenblum D, Ciccarone D. Illicit fentanyls in the opioid street market: desired or imposed? Addiction. 2019;114(5):774-80.

15. Carlson RG, Nahhas RW, Martins SS, Daniulaityte R. Predictors of transition to heroin use among initially non-opioid dependent illicit pharmaceutical opioid users: a natural history study. Drug Alcohol Depend. 2016;160:127-34.

16. Iqvia Institute for Human Data Science. Research Support 2019. https:// www.iqvia.com/institute/research-support.

17. Schanzer D, Pogany L, Aho J, Tomas K, Gale-Rowe M, Kwong J, et al. Can we eliminate hepatitis C?: impact of availability of direct-acting antivirals for hepatitis C on Canadian hospitalization rates, 2012-2016. Can Commun Dis Rep. 2018:44(7-8):150.

18. ClHI. Pan-Canadian Trends in the Prescribing of Opioids and Benzodiazepines, 2012 to 2017. Ottawa: Canadian Institutes for Health Information; 2018. https://www.cihi.ca/sites/default/files/document/opioidprescribing-june2018-en-web.pdf. Accessed: 15 Aug 2019

19. WHO Collaborating Centre for Drug Statistics Methodology. ATC/DDD index Geneva, Switzerland: World Health Organization (WHO) http://www.whocc no/atc_ddd_index/. Accessed: 15 Aug 2019.

20. Svendsen K, Borchgrevink P, Fredheim O, Hamunen K, Mellbye A, Dale O. Choosing the unit of measurement counts: the use of oral morphine equivalents in studies of opioid consumption is a useful addition to defined daily doses. Palliat Med. 2011;25(7):725-32.

21. Fischer B, Jones $\mathbf{W}$, Rehm J. Trends and changes in prescription opioid analgesic dispensing in Canada 2005-2012: an update with a focus on recent interventions. BMC Health Serv Res. 2014;14(1):90.

22. Gomes T, Khuu W, Martins D, Tadrous M, Mamdani MM, Paterson JM, et al. Contributions of prescribed and non-prescribed opioids to opioid related deaths: population based cohort study in Ontario, Canada. BMJ. 2018;362: k3207.

23. Fischer B, Vojtila L, Rehm J. The 'fentanyl epidemic'in Canada-some cautionary observations focusing on opioid-related mortality. Prev Med. 2018;107:109-13.

24. Baldwin N, Gray R, Goel A, Wood E, Buxton JA, Rieb LM. Fentanyl and heroin contained in seized illicit drugs and overdose-related deaths in British Columbia, Canada: an observational analysis. Drug Alcohol Depend. 2018:185:322-7.

25. Fischer B, Varatharajan T, Shield K, Rehm J, Jones W. Crude estimates of prescription opioid-related misuse and use disorder populations towards informing intervention system need in Canada. Drug Alcohol Depend. 2018; 189(1):76-9.

26. Murphy Y, Goldner E, Fischer B. Prescription opioid use, harms and interventions in Canada: a review update of new developments and findings since 2010. Pain Physician. 2015;18:E605-E14.

27. Mars SG, Bourgois P, Karandinos G, Montero F, Ciccarone D. "Every 'never' ever said came true": transitions from opioid pills to heroin injecting. Int J Drug Policy. 2014;25(2):257-66.

28. Babor T, Caulkins J, Fischer B, Foxcroft D, Humphreys K, Medina-Mora ME, et al. Drug policy and the public good. New York City: Oxford University Press; 2018.

29. Wood E. Strategies for reducing opioid-overdose deaths - lessons from Canada. N Engl J Med. 2018:378(17):1565-7.

30. Fairbairn N, Coffin PO, Walley AY. Naloxone for heroin, prescription opioid, and illicitly made fentanyl overdoses: challenges and innovations responding to a dynamic epidemic. Int J Drug Policy. 2017;46:172-9.

31. Vojtila L, Pang M, Goldman B, Kurdyak P, Fischer B. Non-medical opioid use, harms, and interventions in Canada-a 10-year update on an unprecedented substance use-related public health crisis. Drugs Educ Prev Policy. 2019:(epublished 7 Aug 2019).
32. Saloner B, McGinty EE, Beletsky L, Bluthenthal R, Beyrer C, Botticelli M, et al. A public health strategy for the opioid crisis. Public Health Rep. 2018;133: 24S-34S.

33. Fischer B, Pang M, Tyndall M. Applying principles and practices of injury and infectious disease control to the opioid mortality epidemic in North America: critical intervention gaps detrimental to a public health response. $J$ Public Health. 2019 (e-published 10 Dec 2019)

34. CBC News. 'Safe supply' program will distribute free opioids to entrenched users Vancouver: British Columbia: CBC News; 2019. https://www.cbc.ca/ news/canada/british-columbia/phs-injectable-dilaudid-programlaunching-1.4965641. Accessed: 15 Aug 2019.

\section{Publisher's Note}

Springer Nature remains neutral with regard to jurisdictional claims in published maps and institutional affiliations.
Ready to submit your research? Choose BMC and benefit from:

- fast, convenient online submission

- thorough peer review by experienced researchers in your field

- rapid publication on acceptance

- support for research data, including large and complex data types

- gold Open Access which fosters wider collaboration and increased citations

- maximum visibility for your research: over $100 \mathrm{M}$ website views per year

At BMC, research is always in progress.

Learn more biomedcentral.com/submissions 